\title{
Clinical Presentation of Crohn's Disease. Association between Familial Disease, Smoking, Disease Phenotype, Extraintestinal Manifestations and Need for Surgery
}

\author{
Peter Laszlo Lakatos', Ferenc Szalay¹, Zsolt Tulassay², Tamas Molnar33, Agota Kovacs4 \\ Beata Gasztonyi5, J anos Papp1 and the Hungarian IBD Study Group*, Laszlo Lakatos6 \\ 11st Department of Medicine and 22nd Department of Medicine, Semmelweis University, Budapest \\ 31st Department of Medicine, University of Szeged, Szeged, \\ 4Department of Gastroenterology, P $\equiv$ fi Hospital, Budapest, 51st Department of Medicine \\ University of Pecs Medical School, Pecs, \\ Veszprem, Hungary \\ Corresponding Author: Peter Laszlo Lakatos, MD, PhD, 1st Department of Medicine \\ Semmel weis University, Koranyi str. 2/A, H-1083 Hungary \\ Tel: +36 1210 0278/1500, Fax: +36 1313 0250, E-mail: kislakpet@bel 1.sote.hu
}

\begin{abstract}
Background/Aims: Recent molecular data suggest that genetic factors may underlie the disease heterogeneity observed in Crohn's disease (CD). It was also suggested that familial inflammatory bowel disease (IBD) is a homogenous subgroup, phenotypically different from sporadic disease. Our aim was to determine the dinical presentation in a large CD population.

Methodology: $564 \mathrm{CD}$ patients (m/f: 278/286, age: 37.4 (SD 12.7) yrs, duration: 8.4 (7.1) yrs) were included. Disease phenotype was determined according to Vienna dassification. Familial disease, extraintestinal manifestations (EIM), need for surgery and smoking habits were also analyzed.

Results: Familial IBD was present in 73 (12.9\%) patients. Age at onset and presence of EI Ms was asso-
\end{abstract}

ciated with familial disease. Penetrating (44.6\% vs. $<10 y$ rs: $29.1 \%, \mathrm{P}<0.0001$ ) and ileocolonic disease (54.4\% vs. $42.8 \%, P=0.03$ ) were more common in patients with a disease duration of $\geq 10 y r s$. In a logistic regression model female gender, colonic/ileocolonic location, smoking and familial IBD were independent risk factors for EIMs, while ileal and non-inflammatory disease increased the risk for resections. Smoking was also associated with frequent relapses.

Conclusions: Familial IBD was associated with the presence of EIMs, while ileal involvement and noninflammatory behavior independently increased the risk for surgery. Since penetrating and extensive disease was more frequent in patients with longer disease duration our data support a possible change in location and behavior during the course of disease.

\section{INTRODUCTION}

Inflammatory bowel diseases (IBD) are multifactorial, polygenic diseases with probable genetic heterogeneity. In this hypothesis, different genetic backgrounds may explain different dinical patterns of the disease (1-3). In addition to genetic predisposition, various environmental and host factors (e.g. genetic-, epithelial-, immune and non-immune) play a major role in the pathogenesis of IBD. Crohn's disease (CD) is a chronic inflammatory disorder of the gastrointestinal tract. Extensive heterogeneity is observed in terms of disease presentation, behavior, and response to treatment (4-6).

$C D$ has a strong genetic component; recently NOD2/CARD15 mutations were shown by independent groups to be associated with susceptibility to $C D$ $(7,8)$. However there were significant geographical differences regarding the frequency of these alleles, as Hepato-Gastroenterology 2005; 52:817-822 (c) H.G.E. U pdate Medical Publishing S.A., Athens-Stuttgart they are not found in J apan and China $(9,10)$, and other disease modifying genes may also exist (8). A lifetime risk of $10-20 \%$ to develop IBD was reported in the presence of an affected first degree relative $(4,11,12)$. CD patients have an affected first-degree relative with CD in $2.2-16.2 \%$ of cases and with IBD in $5.2-22.5 \%$ of cases (13). The concordance rate of affected siblings was reported to be as high as $60-80 \%$ (14).

Disease phenotypes that may be genetically determined have been suggested, including: age at onset, disease site, behavior, presence of extraintestinal manifestation and need for surgery (11,14-16). Age of onset was found to be significantly less in familial compared to sporadic disease $(17,18)$, but this was not replicated in all studies (19). Polito et al. (18) also showed that stratification for age at diagnosis of $C D$ is associated to age-specific phenotypes. Concordance rates of 56-86\% for location and $49-82 \%$ for behavior were reported in
KEY WORDS:

IBD;

Crohn's disease; Phenotype; Familial

ABBREVIATIONS: Crohn's Disease (CD); Inflammatory Bowel Disease (IBD);

Extraintestinal Manifestations (EIM); Primary Sclerosing Cholangitis (PSC); Odds Ratio (OR) 
parent-child pairs and sibling pairs $(14,17)$. There is no consistent difference in location and behavior of $C D$ between familial and non-familial (sporadic) disease. Higher frequency of ileal disease, less ileocolonic disease (19), more colonic disease (20) and also no difference (21) was reported in familial patients.

In addition to genetic factors, environmental contributions significantly affect clinical phenotypes and disease course. The percentage of current smokers in a group of patients with CD is significantly higher than that observed in a control population matched for sex and age (45-55 vs. 30-40\%) (6). A meta-analysis by Calkins (22) and a study by our group (6) estimated an odds ratio of around 2.0 in current smokers when compared to lifetime non-smokers to develop CD. Tobacco use had been a risk factor for ileal rather than coloniconly disease and, particularly heavy tobacco use, increases disease activity, risk of surgery, postoper ative relapses, and accumulation of fistulae and abscesses $(23,24)$. However, the harmful effect of smoking on the course of $C D$ is not a universal finding. No differences were found in the need for operation or for immunosuppressants between smokers and non-smokers in patients from Israel $(25,26)$, and patients with colonic involvement only are less sensitive to the harmful

TABLE 1 Clinical Characteristics of Crohn's Disease Patients, according to the Presence of Familial IBD

\begin{tabular}{|c|c|c|c|}
\hline & $\begin{array}{c}\text { Total } \\
(n=564)\end{array}$ & $\begin{array}{c}\text { Familial IBD } \\
\qquad(n=73)\end{array}$ & $\begin{array}{c}\text { Sporadic IBD } \\
(n=491)\end{array}$ \\
\hline Male/female & $278 / 286$ & $33 / 40$ & $245 / 246$ \\
\hline Age (years) & $37.3 \pm 12.7$ & $36.3 \pm 12.6$ & $37.5 \pm 12.8$ \\
\hline Age at presentation (years) & $28.9 \pm 11.5$ & $28.1 \pm 11.4$ & $29.1 \pm 12.0$ \\
\hline Duration (years) & $8.4 \pm 7.1$ & $8.3 \pm 6.6$ & $8.4 \pm 7.2$ \\
\hline \multirow[t]{4}{*}{ Location } & $140(24.8 \%)$ & $18(24.6 \%)$ & $122(24.8 \%)$ \\
\hline & $155(27.5 \%)$ & 24 (32.9\%) & $131(26.7 \%)$ \\
\hline & 264 (46.8\%) & 31 (42.5\%) & $233(47.5 \%)$ \\
\hline & $5(0.9 \%)$ & 0 & $5(1.0 \%)$ \\
\hline \multirow[t]{3}{*}{ Behavior } & 232 (41.1\%) & 28 (38.4\%) & 204 (41.6\%) \\
\hline & $138(24.5 \%)$ & $19(26.0 \%)$ & $119(24.2 \%)$ \\
\hline & 194 (34.4\%) & $26(35.6 \%)$ & $168(34.2 \%)$ \\
\hline Perianal disease, n (\%) & $152(26.9 \%)$ & 26 (35.6\%)* & $126(25.7 \%)^{*}$ \\
\hline Frequent relapse, n (\%) & $203(36.0 \%)$ & $32(43.9 \%)$ & $171(34.9 \%)$ \\
\hline $\begin{array}{l}\text { Extraintestinal } \\
\text { manifestations, n (\%) }\end{array}$ & $202(35.8 \%)$ & 36 (49.3\%)\# & 166 (33.8\%)\# \\
\hline Arthritis, n (\%) & $173(30.7 \%)$ & 34 (46.6\%)\#\# & 139 (28.3\%)\#\# \\
\hline Occular, n (\%) & $28(5.0 \%)$ & $4(5.5 \%)$ & $24(4.9 \%)$ \\
\hline $\begin{array}{l}\text { Erythema nodosum/ } \\
\text { Pyoderma, n (\%) }\end{array}$ & 51 (9.1\%) & $4(5.5 \%)$ & $47(9.6 \%)$ \\
\hline PSC, n (\%) & $22(3.9 \%)$ & $1(1.4 \%)$ & $21(4.3 \%)$ \\
\hline Steroid use/refractory, & $475(84.2 \%) /$ & / 64 (87.7\%) / & $411(83.7 \%) /$ \\
\hline $\mathrm{n}(\%)$ & $64(13.5 \%)$ & $13(20.3 \%)$ & $51(12.4 \%)$ \\
\hline Azathioprine/refractory & $349(61.9 \%) /$ & $51(69.9 \%) /$ & $298(60.7 \%) /$ \\
\hline $\mathrm{n}(\%)$ & $24(6.9 \%)$ & $5(9.8 \%)$ & 19(6.4\%) \\
\hline Operation, n (\%) / & $237(42.0 \%) /$ & / $27(37.0 \%) /$ & $210(42.9 \%) /$ \\
\hline multiple resection (\%) & 64 (11.3\%) & $6(8.2 \%)$ & 58 (11.8\%) \\
\hline \multirow{3}{*}{ Smoking habits } & 328 (58.1\%) & $40(54.8 \%)$ & $288(58.6 \%)$ \\
\hline & $184(32.6 \%)$ & 25 (34.3\%) & $159(32.4 \%)$ \\
\hline & $52(9.3 \%)$ & $8(10.9 \%)$ & $44(9.0 \%)$ \\
\hline
\end{tabular}

${ }^{*} \mathrm{P}=0.051,{ }^{\mathrm{P}}=0.01, \# \# \mathrm{P}=0.002$ between patients with family history of IBD and without by Yates-corrected $\chi^{2}$. effect of smoking (27).

A positive association between disease location and behavior was also reported (28), however this was not replicated in all studies (29). Patients with perianal disease were more likely to have colonic disease (30) whereas patients with internal fistulizing disease were more likely to have ileal or ileocolonic disease and are more likely to require intestinal resection (31).

In this study we investigated disease phenotype in a large Crohn's disease population. We also aimed to investigate the association between familial disease, smoking and disease phenotype, and identify factors affecting disease phenotype, presence of extraintestinal manifestations and need for resection.

\section{METHODOLOGY}

564 unrelated Hungarian patients with CD (male/female: 278/286, age: 37.4 (SD 12.7) years) were investigated. CD patients with a convenient diagnosis and with a follow-up time of at least one year were included. Average disease duration was: $8.4(7.1)$ years. The diagnosis was based on Lennard-J ones criteria (32) and each patient has read and signed the informed consent form.

The disease phenotype was assessed by filling in a questionnaire. Age, age at presentation, familial IBD, location, behavior [according to the Vienna classification (28): A1: <40 years at onset, A2: >40 years at onset, L1: ileal, L2: colonic, L3: ileocolonic, L4: upper GI, B1: inflammatory, B2: stenosing, B3: penetrating], perianal involvement, frequent flare up, presence of extraintestinal manifestations [EIM; arthritis: periferal and axial, ocular manifestations: conjunctivitis, uveitis, iridocyclitis, skin lesions: erythema nodosum, pyoderma gangrenosum, and hepatic manifestations: primary sclerosing cholangitis (PSC)], therapeutic effectiveness (e.g. steroid and/or immunosuppressive use and resistance), need for surgery (resections), and smoking habits were determined (Table 1). Familial IBD was present in 73 patients $(12.9 \%, 41$ 1st degree relatives with $C D$ and 11 with $U C$; 8 2nd degree relatives with $C D$ and 13 with $U C$ ).

The study was approved by the Semmelweis University Regional and Institutional Committee of Science and Research Ethics (81/2003).

Statistical methods: Variables were tested for normality by Shapiro Wilk's W test. T-test with separate variance estimates, ANOVA, factorial ANOVA with post hoc Scheffe test, $\chi^{2}$-test and $\chi^{2}$-test with Yates correction and logistic regression was used to test differences in disease phenotype between subgroups of CD patients. Odds ratios (OR) were cal culated. Pearson correlation was used to compare age at onset, age class and year of birth data. A $P$ value of $<0.05$ was considered as significant. For the statistical analysis Statistica 6.1 (Statsoft Inc, OK, USA) was used.

\section{RESULTS}

Age at onset was 28.9 (SD 11.5) years and disease 


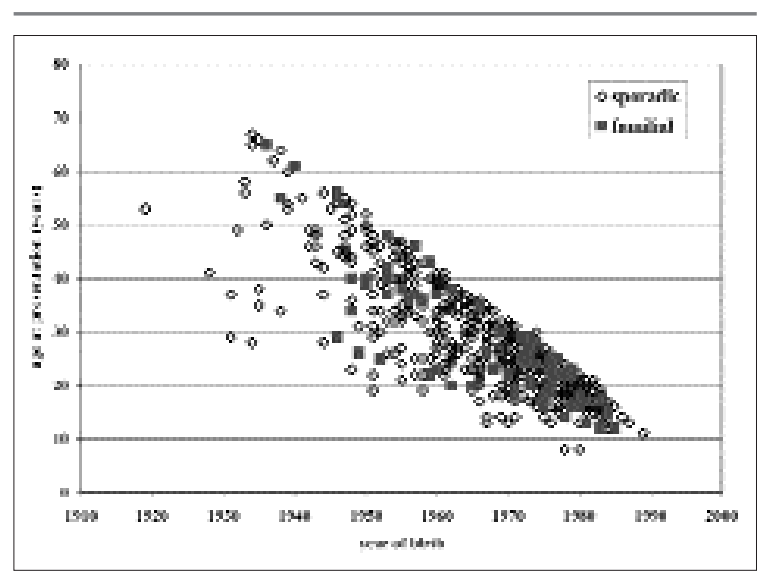

FIGURE 1 Association between age at onset and year of birth in $C D$ patients. $r=-0.83, P<0.0001$ in sporadic $C D$ patients and $r=-0.85$, $\mathrm{P}<0.0001$ in patients with familial IBD.

duration 8.4 (7.1) years, not different in patients with and without familial IBD (Table 1). Age, age at onset and duration was mildly lower in males [35.0 (11.7) yrs vs. 39.7 (13.3) yrs, $P=0.00001$ age at onset: 27.4 (11.2) yrs vs. 30.5 (11.6) yrs, $\mathrm{P}=0.001$ and duration 7.6 (6.3) yrs vs. 9.1 (7.7) yrs, $P=0.01$ ]. There was no association between age at onset and familial IBD (Table 1). A strong negative correlation was found between age at onset and year of birth $(r=-0.83, p<0.0001$, Figure 1). No difference was detected between familial IBD and sporadic cases.

Disease location was predominantly ileocolonic (L3: $46.8 \%$ ), while disease behavior was more balanced. Ileocolonic location was more frequent in patients with penetrating behavior (54.1\% vs. others $42.9 \%$ ) while inflammatory behavior was more fre quent in patients with colonic disease (34.5\% vs. others $22.8 \%, \mathrm{P}=0.004$, Table 2). Age at onset was also lower in patients with ileocolonic (L3: 26.6 yrs vs. L 1: 30.5 yrs and $L 2$ : 31.6 yrs, $P=0.01$ and $P=0.0004$ by post hoc Scheffe test) or penetrating (27.1 yrs vs. B1: 29.8 yrs, B3: 30.1 yrs, $P<0.048$ and $P=0.041$ ) disease. In patients with a disease duration of $\geq 10$ yrs B3 (44.6\% vs. <10 yrs: $29.1 \%)$ and L3 disease (54.4\% vs. $42.8 \%)$ was more common while B1 ( $27.5 \%$ vs. $48.3 \%$, $\mathrm{P}<0.0001)$ and $\mathrm{L} 1$ (18.6\% vs. $28.0 \%, \mathrm{P}=0.03)$ was less prevalent (Figure 2). Smoking was associated with disease behavior but not location; penetrating disease was more frequent in patients currently smoking (41.9\% vs. $29.5 \%, \mathrm{P}=0.02$ ).

There was a tendency of increased frequency of perianal disease in patients with familial IBD $(P=0.051)$. In a logistic regression analysis investigating theassociation between gender, location, behavior, familial IBD and smoking; non-inflammatory behavior $(\mathrm{OR}=1.89,95 \% \mathrm{Cl}=1.30-2.75, \mathrm{P}=0.001)$ and smoking $(\mathrm{OR}=1.67,95 \% \mathrm{Cl}=1.16-2.39, \mathrm{P}=0.005)$ were independent risk factors for frequent relapses.

Extraintestinal manifestations were more fre quent in patients with familial IBD $(49.3 \%$ vs. sporadic: $33.8 \%, \mathrm{P}=0.01)$ and females (39.9\% vs. males:
$31.6 \%, P=0.04$ ). Location (L2-3: $41.3 \%$ vs. L1 $22.1 \%$ ) was also associated to the presence of EIMs in univariate analysis. In a logistic regression analysis investigating the association between gender, location, behavior, familial IBD, smoking and the presence of EIMs gender, behavior, smoking and familial disease were independently associated with EIMs (Table 3). Arthritis was also more frequent in patients with familial IBD (46.6\% vs. $28.3 \%, \mathrm{P}=0.002)$. Ileocolonic or colonic location $(\mathrm{OR}=4.29,95 \% \mathrm{Cl}=1.51-12.18$, $\mathrm{P}=0.006)$ and smoking $(\mathrm{OR}=1.88,95 \% \mathrm{Cl}=1.04-3.39$, $\mathrm{P}=0.02$ ) increased the risk of cutaneous manifestations.

Steroid and azathioprine use was more frequent in patients with ileocolonic (steroid use; L3: $89 \%$ vs. L 1: 74.3\%, L2: 85.2\%, $P=0.0017$, azathioprine use; $68.9 \%$ vs. L1: $52.1 \%$, L2: $58.7 \%, \mathrm{P}=0.007$ ) or penetrating disease (steroid use: $90.7 \%$ vs. L1: $76.7 \%$, L2: $87.7 \%$, $\mathrm{P}=0.0017$, azathioprine use: $73.7 \%$ vs. L 1: $49.1 \%$, L 2: $66.7 \%, \mathrm{P}=0.007)$. In a logistic regression analysis both

TABLE 2 Association between Disease Location and Behavior in Patients with Crohn's Disease

\begin{tabular}{lccccc} 
& Ileal & Colonic & Ileocolonic & Upper GI & Total \\
\hline Inflammatory & $54(23.3 \%)$ & $79(34.0 \%)$ & $96(41.4 \%)$ & $3(1.3 \%)$ & 232 \\
\hline Stricturing & $46(33.3 \%)$ & $27(19.6 \%)$ & $63(45.7 \%)$ & $2(1.4 \%)$ & 138 \\
\hline Penetrating & $40(20.6 \%)$ & $49(25.3 \%)$ & $105(54.1 \%)$ & 0 & 194 \\
\hline Total & 140 & 155 & 264 & 5 & 564 \\
\hline P & & & & &
\end{tabular}

$\mathrm{P}=0.004$.
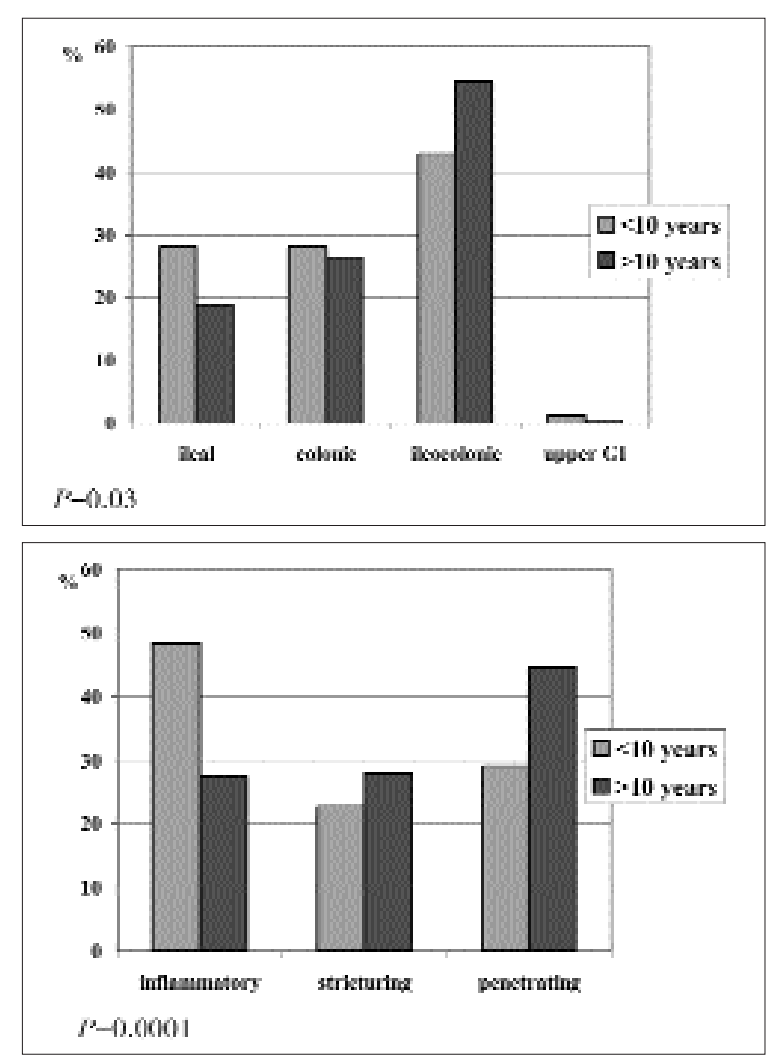

FIGURE 2 Association between Disease Location, Behavior and Duration in CD Patients with More or Less than 10 Years Disease Duration 
TABLE 3 Logistic Regression: Association between Gender, Disease

Location, Behavior, Familial Disease, Smoking and the Presence of Extraintestinal Manifestations

\begin{tabular}{lcccc} 
Factor & Coefficient & P value & OR & 95\%Cl \\
\hline Female gender & 0.409 & 0.026 & 1.51 & $1.05-2.16$ \\
\hline Ileocolonic or colonic location & 0.902 & $<0.0001$ & 2.47 & $1.57-3.88$ \\
\hline Non-inflammatory behavior & 0.308 & 0.10 & 1.36 & $0.94-1.96$ \\
\hline Familial disease & 0.628 & 0.016 & 1.88 & $1.13-3.12$ \\
\hline Smoking & 0.440 & 0.017 & 1.55 & $1.08-2.22$ \\
\hline
\end{tabular}

The coefficient is equivalent to the natural log of the odds ratio (OR).

TABLE 4 Logistic Regression: Association between Gender, Disease Location, Behavior, Familial Disease, Smoking and the Need for Resection

\begin{tabular}{lcccc} 
Factor & Coefficient & P value & OR & 95\%Cl \\
\hline Female gender & 0.042 & 0.84 & 1.04 & $0.69-1.57$ \\
\hline Ileal involvement & 1.28 & $<0.0001$ & 3.59 & $2.22-5.81$ \\
\hline Non-inflammatory behavior & 2.64 & $<0.0001$ & 14.10 & $8.69-22.77$ \\
\hline Extraintestinal manifestation & -0.29 & 0.18 & 0.75 & $0.49-1.15$ \\
\hline Familial disease & -0.34 & 0.28 & 0.72 & $0.39-1.32$ \\
\hline Smoking & -0.35 & 0.10 & 0.71 & $0.46-1.06$ \\
\hline The
\end{tabular}

The coefficient is equivalent to the natural log of the odds ratio (OR).

location and behavior were independent predictors of steroid $\left(P_{\text {location }}=0.001, P_{\text {behavior }}<0.0001\right)$ and azathioprine use ( $P_{\text {location }}=0.002$, $\left.P_{\text {behavior }}<0.0001\right)$.

Logistic regression analysis was used to explore the effect of familial disease, gender, location, behavior and smoking on the need for surgery. Non-inflammatory behavior and ileal involvement were positively, independently associated to the need for resections but not gender or familial disease (Table 4). This association was analyzed also for the need of multiple resections: the effect of ileal involvement $(\mathrm{OR}=2.91$, $95 \% \mathrm{Cl}=1.27-6.65, \mathrm{P}=0.01)$ and non-inflammatory behavior $(\mathrm{OR}=15.7,95 \% \mathrm{Cl}=4.8-50.9)$ remained unchanged.

\section{DISCUSSION}

In this study we investigated the characteristic traits of familial IBD and association between clinical data and disease phenotype. In concordance with previous studies $(11,17,18)$ age at onset was not associated with familial disease with identical disease duration and similar smoking habits. Furthermore we confirmed the findings of Poilito et al. (18), who showed age-specific phenotype according to the age at diagnosis. In our study more stricturing (A1: $37.8 \%$ vs. A2: $17.7 \%, \mathrm{P}=0.0007)$ and ileocolonic (50.0\% vs. $31.3 \%$, $\mathrm{P}=0.004)$ disease was present in $\mathrm{Al}$ patients $(<40$ years old at diagnosis), while colonic disease (A2: $38.5 \%$ vs. A1: $25.2 \%$ ) and inflammatory behavior (50.0\% vs. $39.3 \%$ ) was more common in patients with A2 disease.

We found no association between disease location, behavior and familial IBD. There is also no consistency in difference in location and behavior of $C D$ between familial and non-familial (sporadic) disease in the literature. In two recent studies using the Vienna classification, Halme et al. (19) demonstrated a greater frequency of ileal disease in familial disease ( 38 versus $21 \%$ ) and less ileocolonic ( 35 vs. $50 \%$ ). Freeman \& al. (20) also found less ileocolonic disease in familial disease (32 vs. 43\%) but purely colonic disease (46 vs. $29 \%$ ) was more frequent in familial cases. Hampeet al. (21) found no difference between familial and sporadic disease in terms of disease behavior. Furthermore Carbonnel \& al. (33) found more operations for perforating disease in familial disease.

A possible explanation for this large variation might be that the patient groups may differ also in terms of other genetic and/or environmental factors (like smoking). In our study no difference was found in smoking habits between familial and sporadic patients. A further limitation could be if the analysis was not done at the same timepoint, as disease phenotype is dynamic and changes over time $(29,34)$, as found also in our study. Disease location was more extensive and behavior shifted towards higher prevalence of penetrating disease in patients with longer disease duration.

Extraintestinal manifestations (EIMS) were found in one third of the patients. The presence of extraintestinal manifestations was higher in familial CD cases and -beside female gender, colonic and ileocolonic disease and smoking- familial disease was an independent risk factor for EIMs in a logistic regression analysis. High concordance rates for extraintestinal manifestations were reported previously in subsequent CD generation (67-80\%) (35). Furthermore in the study of Hofer $\&$ al. behavior, male gender aru corticosteroid treatment and the presence of extraintestinal manifestations were found to be associated with earlier reoperations. In contrast in our study the presence of EI Ms was not associated to need for surgery.

An important question is the dinical outcome measured by the number of relapses and the need for CD associated surgery. We found non-inflammatory behavior and smoking to be independent predictors of frequent relapses. In the study of Cosnes \& al. (37) current smoking increases the risk of flare-up compared to never-smokers by more than $50 \%$, the same extent found also in our study. The effect of smoking in that study was independent of gender, age, duration of disease and current therapy. Patients with colonic location were less sensitive. In concordance with previous data $(38,39)$ smoking was associated with more frequent penetrating disease.

The deleterious effect of smoking in CD was particularly manifest in patients who had been operated on in previous studies. The cumulative rates of dinical and surgical recurrence were found to be consistently more elevated in smokers compared to non-smokers $(40,41)$.

The need for steroids and immunosuppressants was reported to be also increased in smokers compared to non-smokers (23). Moreover, therisk of being operated on at least once during disease course was also increased in smokers in most previous studies (42). In our study ileal disease and most markedly 
non-inflammatory behavior were associated with increased risk for surgery and, in concordance with data in patients from Israel $(45,46)$, no differences were found in the need for operation or for immunosuppressants between smokers and non-smokers. Of note, in the study of Cosnes et al. immunosuppressive therapy was suggested to neutralize the effect of smoking on the need for surgery (43).

In IBD, anticipation was originally suggested by studies that demonstrated a younger age at onset in familial compared to sporadic disease, and younger age at onset and more serious disease in subsequent family generations $(17,29,44)$. However, in concordance with more recent studies $(45,46)$, our results suggested that anticipation does not occur in IBD. In this study, we could not prove an earlier age at onset, or a difference in disease location, behavior or increased need for aggressive immunosuppressive therapy and surgery in patients with familial disease

\section{RE FE RE NCES}

1 Gasche C, Alizadeh BZ, Pena AS: Genotype-phenotype correlation: how many disorders constitute inflammatory bowel diseases? Eur J Gastroenterol Hepatol 2003; 15:599606.

2 Tytgat KM, Lygidakis NJ : Crohn's disease. Hepatogastroenterology 1990; 37:1-5.

3 Koutroubakis I, Manousos ON, Meuwissen SG, Pena AS: Environmental risk factors in inflammatory bowel disease. Hepatogastroenterology 1996; 43:381-93.

4 Koutroubakis IE, Petinaki E, Mouzas IA, Vlachonikolis IG, Anagnostopoulou E, Castanas E, Maniatis AN, Kouroumalis EA: Anti-Saccharomyces cerevisiae mannan antibodies and antineutrophil cytoplasmic autoantibodies in Greek patients with inflammatory bowel disease. Am J Gastroenterol 2001; 96:449-54.

5 Podolsky DK: I nflammatory bowel disease. N Engl J Med 2002; 347:417-428.

6 Lakatos L, Mester G, Erdelyi Z, Balogh M, Szipocs I, Kamaras G, Lakatos PL: Striking elevation in incidence and prevalence of inflammatory bowel disease in a province of western Hungary between 1977-2001. World J Gastroenterol 2004; 10:404-409.

7 Hugot J P, Chamaillard M, Zouali H, Lesage S, Cezard J P, Belaiche J, Almer S, Tysk C, O'Morain CA, Gassull $M$, Binder V, Finkel $Y$, Cortot $A$, Modigliani R, Laurent-Puig P, Gower-Rousseau C, Macry J , Colombel J F, Sahbatou M, Thomas G: Association of NOD2 leucine-rich repeat variants with susceptibility to Crohn's disease. Nature 2001; 411:599-603.

8 Ahmad T, Tamboli CP, J ewell DP, Colombel J F : Clinical relevance of advances in genetics and pharmacogenetics of IBD. Gastroenterology 2004; 128:1533-1549.

9 Inoue N, Tamura K, Kinouchi Y, Fukuda Y, Takahashi S, Ogura Y, Inohara N, Nunez G, Kishi Y, Koike Y, Shimosegawa T, Shimoyama T, Hibi T: Lack of common NOD2 variants in J apanese patients with Crohn's disease. Gastroenterology 2002; 123:86-91.

10 Guo QS, Xia B, J iang Y, Qu Y, Li J : NOD2 3020insC frameshift mutation is not associated with inflammatory bowel disease in Chinese patients of Han nationality. World J Gastroenterol 2004; 10:1069-1071.

11 Halfvarson J , Bodin L, Tysk C, Lindberg E, J arnerot G: Inflammatory bowel diseases in a Swedish Twin cohort: a long-term follow-up of concordance and clinical characteristics. Gastroenterology 2003; 124:1767-1773.

12 Peeters M, Cortot A, Vermiere S, Colombel J F : Familial and sporadic inflammatory bowel diseases: different entities? I nflamm Bowel Dis 2000; 6:314-320.

13 Russell RK, Satsangi J : IBD: a family affair. Best Pract compared to sporadic patients with identical disease duration and similar smoking habits. In contrast, age at onset became lower in the later diagnosed patients, both in sporadic and familial IBD.

In summary, the presence of EIMs was associated with familial IBD. Familial disease, female gender, colonic involvement and smoking were independently associated with EIMs, while ileal disease, non-inflammatory behavior but not smoking were independent risk factors increasing the risk for surgery. Since penetrating and more extensive disease was more common in patients with longer disease duration our data support a possible change in disease location and behavior during the course of the disease.

\section{ACKNOWLE DGME NTS}

The authors like to thank Dr. Peter Vargha for help in performing the statistical analysis.

Res Clin Gastroenterol. 2004; 18:525-39.

14 Bayless TM, Tokayer AZ, Polito J M, Quaskey, Mellits ED, Harris ML: Crohn's disease: concordance for site and clinical type in affected family members-potential hereditary influences. Gastroenterology 1996; 111:573-579.

15 Lakatos L, Pandur T, David G, Balogh Z, Kuronya P, Tollas A, Lakatos PL: Association of extraintestinal manifestations of inflammatory bowel disease in a province of western Hungary with disease phenotype: results of a 25year follow-up study. World J Gastroenterol 2003; 9:23002307.

16 Grandbastien B, Peeters M, Franchimont D, GowerRousseau C, Speckel D, Rutgeerts P, Belaiche J , Cortot A, Vlietnick R, Colombel J F : Anticipation in familial Crohn's disease. Gut 1998; 42:170-174.

17 Colombel J F, Grandbastien B, Gower-Rousseau C, Plegat S, Evrard J P, Dupas J L, Gendre J P, Modigliani R, Belaiche J, Hostein J, Hugot J P, van Kruiningen $\mathbf{H}$, Cortot A: Clinical characteristics of Crohn's disease in 72 families. Gastroenterology 1996; 111:604-607.

18 Polito J M, Childs B, Mellits ED, Tokayer AZ, Harris ML, Bayless TM: Crohn's disease: influence of age at diagnosis on site and clinical type of disease. Gastroenterology 1996; 111:580-586.

19 Halme L, Turunen U, Helio T, Paavola P, Walle T, Miettinen A, J arvinen H, Kontula K, Farkkila M: Familial and sporadic inflammatory bowel disease: comparison of clinical features and serological markers in a genetically homogeneous population. Scand J Gastroenterol 2002; 37:692-698.

20 Freeman $\mathbf{H J}$ : Familial Crohn's disease in single or multiple first-degree relatives. J Clinical Gastroenterology 2002; 35:9-13.

21 Hampe J, Heymann K, Kruis W, Raedler A, Folsch UR, Schreiber S: Anticipation in inflammatory bowel disease: a phenomenon caused by an accumulation of confounders. AmJ Med Genet 2000; 92:178-183.

22 Calkins BM: A meta-analysis of the role of smoking in inflammatory bowel disease. Dig Dis Sci 1989; 34:18411854.

23 Russel MG, Volovics A, Schoon EJ, van Wijlick EH, Logan RF, Shivananda S, Stockbrugger RW: Inflammatory bowel disease: is there any relation between smoking status and disease presentation? European Collaborative IBD Study Group. Inflamm Bowel Dis 1998; 4:182-186.

24 Yamamoto T, Keighley MR: Smoking and disease recurrence after operation for Crohn's disease. Br J Surg 2000; 87:398-404. 
25 Fidder HH, Avidan B, Lahav M, Bar-Meir S, Chowers Y: Clinical and demographic characterization of J ewish Crohn's disease patients in Israel. J Clin Gastroenterol 2003; 36:8-12.

26 Odes HS, Fich A, Reif S, Halak A, Lavy A, Keter D, Eliakim R, Paz J , Broide E, Niv Y, Ron Y, Villa Y, Arber N, Gilat T: Effects of current cigarette smoking on clinical course of Crohn's disease and ulcerative colitis. Dig Dis Sci 2001; 46:1717-1721.

27 Cosnes J : Tobacco and IBD: relevance in the understanding of disease mechanisms and clinical practice. Best Pract Res Clin Gastroenterol 2004; 18:481-496.

28 Gasche C, Scholmerich J, Brynskov J, D'Haens G, Hanauer SB, Irvine EJ , J ewell DP, Rachmilewitz D, Sachar DB, Sandborn W , Sutherland LR: A simple classification of Crohn's disease: report of the Working Party for the World Congresses of Gastroenterology, Vienna 1998. Inflamm Bowel Dis 2000; 6:8-15.

29 Louis E, Collard A, Oger AF, Degroote E, Aboul Nasr EI Yafi F, Beilache J: Behaviour of Crohn's disease according to the Vienna classification:changing pattern over the course of the disease. Gut 2001; 49:777-782.

30 Schwartz DA, Pemberton J H, Sandborn WJ : Diagnosis and treatment of perianal fistulas in Crohn disease. Ann Intern Med 2001; 135:906-918.

31 Veloso FT, Ferreira J T, Barros L, Almeida S: Clinical outcome of Crohn's disease: analysis according to the Vienna classification and clinical activity. Inflamm Bowel Dis 2001; 7:306-313.

32 Lennard-J ones J E: Classification of inflammatory bowel disease. Scand J Gastroenterol 1989; 24(Suppl 170):2-6.

33 Carbonnel F, Macaigne G, Beaugerie L, Gendre J P, Cosnes J : Crohn's disease severity in familial and sporadic cases. Gut 1999; 44:91-95.

34 Cosnes J , Cattan S, Blain A, Beaugerie L, Carbonnel F, Parc R, Gendre J P: Long-term evolution of disease behavior of Crohn's disease. Inflamm Bowel Dis 2002; 8:244-250.

35 Annese V, Andreoli A, Astegiano M, Campieri M, Caprilli R, Cucchiara S, D'Inca R, Giaccari S, Iaquinto G, Lombardi G, Napolitano G, Pera A, Riegler G, Valpiani D, Andriulli A: Clinical features in familial cases of Crohn's disease and ulcerative colitis in Italy: a GISC study. I talian Study Group for the Disease of Colon and Rectum. Am J Gastroenterol. 2001; 96:2939-2945.

36 Hofer B, Bottger T, Hernandez-Richter T, Seifert J K, J unginger $\mathbf{T}$ : The impact of clinical types of disease manifestation on the risk of early postoperative recurrence in Crohn's disease. Hepatogastroenterology 2001; 48:152-155.

37 Cosnes J , Carbonnel F, Carrat F, Beaugerie L, Cattan S, Gendre J : Effects of current and former cigarette smoking on the clinical course of Crohn's disease. Aliment Pharmacol Ther 1999; 13:1403-1411.

38 Picco MF, Bayless TM: Tobacco consumption and disease duration are associated with fistulizing and stricturing behaviors in the first 8 years of Crohn's disease. Am J Gastroenterol 2003; 98:363-368.

39 Louis E, Michel V, Hugot J P, Reenaers C, Fontaine F, Delforge M, EI Yafi F, Colombel J F, Belaiche J : Early development of stricturing or penetrating pattern in Crohn's disease is influenced by disease location, number of flares, and smoking but not by NOD2/CARD15 genotype. Gut 2003; 52:552-557.

40 Cottone M, Rosselli M, Orlando A, Oliva L, Puleo A, Cappello M, Traina M, Tonelli F, Pagliaro L: Smoking habits and recurrence in Crohn's disease. Gastroenterology 1994; 106:643-648.

41 Moskovitz D, McLeod RS, Greenberg GR, Cohen Z: Operative and environmental risk factors for recurrence of Crohn's disease. Int J Colorectal Dis 1999; 14:224-226.

42 Breuer-Katschinski BD, Hollander N, Goebell H: Effect of cigarette smoking on the course of Crohn's disease. Eur J Gastroenterol Hepatol 1996; 8:225-228.

43 Cosnes J , Carbonnel F, Beaugerie L, Le Quintrec Y, Gendre J P: Effects of cigarette smoking on the long-term course of Crohn's disease. Gastroenterology 1996; 110:424431.

44 Polito J M, Rees RC, Childs B, Mendeloff Al, Harris ML, Bayless TM: Preliminary evidence for genetic anticipation in Crohn's disease. Lancet 1996; 347:798-800.

45 Lee J C, Bridger S, McGregor C, Macpherson AJ, J ones J E: Why children with inflammatory bowel disease are diagnosed at a younger age than their affected parent. Gut 1999; 44:808-811.

46 Hampe J, Heymann K, Kruis W, Raedler A, Folsch UR, Schreiber S: Anticipation in inflammatory bowel disease: a phenomenon caused by an accumulation of confounders. Am J Med Genet 2000; 92:178-183.

\section{FOOTNOTE}

*Hungarian IBD Study Group: Semmelweis University, 1st Department of Medicine, Budapest: Peter Fuszek, Peter Vargha; Semmelweis University, 2nd Department of Medicine, Semmelweis University, Budapest: †Laszlo Pronai, Annamaria Nemeth, Pal Miheller; Erzsebet Hospital, 1st Department of Medicine, Budapest: Agota Kovacs, Laszlo Bene; Szent J anos Hospital, 1st Department of Medicine: Gyorgy Szekely; University of Pecs, 1st Department of Medicine, Pecs: Gyula Mozsik; University of Szeged, 1st Department of Medicine, Szeged: Ferenc Nagy, J anos Lonovics; Semmelweis Hospital, 1st Department of Medicine, Miskolc: Laszlo Ujszaszy; University of Debrecen, 2nd Department of Medicine, Debrecen: Istvan Altorjai, Karoly Palatka; Kenezi Gy. County Hospital, 2nd Department of Medicine, Debrecen: Gyula G. Kiss; County Hospital, 2nd Department of Medicine, Zalaegerszeg; Ferenc Tarnok, Markusovszky Hospital, 2nd Department of Medicine, Szombathely: Zoltan Dobronte; Csolnoky F. County Hospital, 1st Department of Medicine, Veszprém: Zsuzsanna Erdelyi, Tunde Pandur, Gabor Mester 